\title{
Advocacy needed for borderline personality disorder
}

$\mathrm{E}$ xperts say that lack of advocacy for patients with borderline personality disorder (BPD) means it garners scant attention or resources and insufficient funding for research. One family says these shortfalls cost them their daughter's life.

Four years after her first suicide attempt Sasha Menu Courey was finally diagnosed with BPD and given treatment. People with BPD have poor ability to regulate their emotions, which leads to amplification of all feelings anger, fear, happiness, sadness sometimes to unbearable levels.

This emotional dysregulation, experienced by $0.5 \%-5.9 \%$ of the population, according to a 2011 Lancet article, manifests itself in a number of ways. Patients may experience a lack of self-identity, trouble with relationships and a severe fear of abandonment. To be diagnosed with BPD, a person must experience at least five of the nine key symptoms.

Risky, impulsive behaviour such as substance or alcohol abuse, and suicidal or self-injuring behaviour are the most dangerous features. About $75 \%$ of patients with BPD self-harm and about $10 \%$ eventually end their own lives.

Despite the severity of the disorder, Dr. Mark Zimmerman, a researcher and professor at Brown Alpert Medical School in Rhode Island, said that BPD is under-funded, under-recognized and often misdiagnosed.

His commentary published in the Journal of Nervous and Mental Disease in January 2015 suggested that although BPD was just as frequent, impairing and lethal - if not more - as bipolar disorder, it receives a tenth of the research funding.

Although the commentary suggests that bipolar disorder is often publicized as underdiagnosed, Zimmerman argues that BPD does not yet have this kind of advocacy. There are relatively few articles about BPD. Little is written about the lack of resources to treat and study it. It is not acknowledged as a serious public health issue.

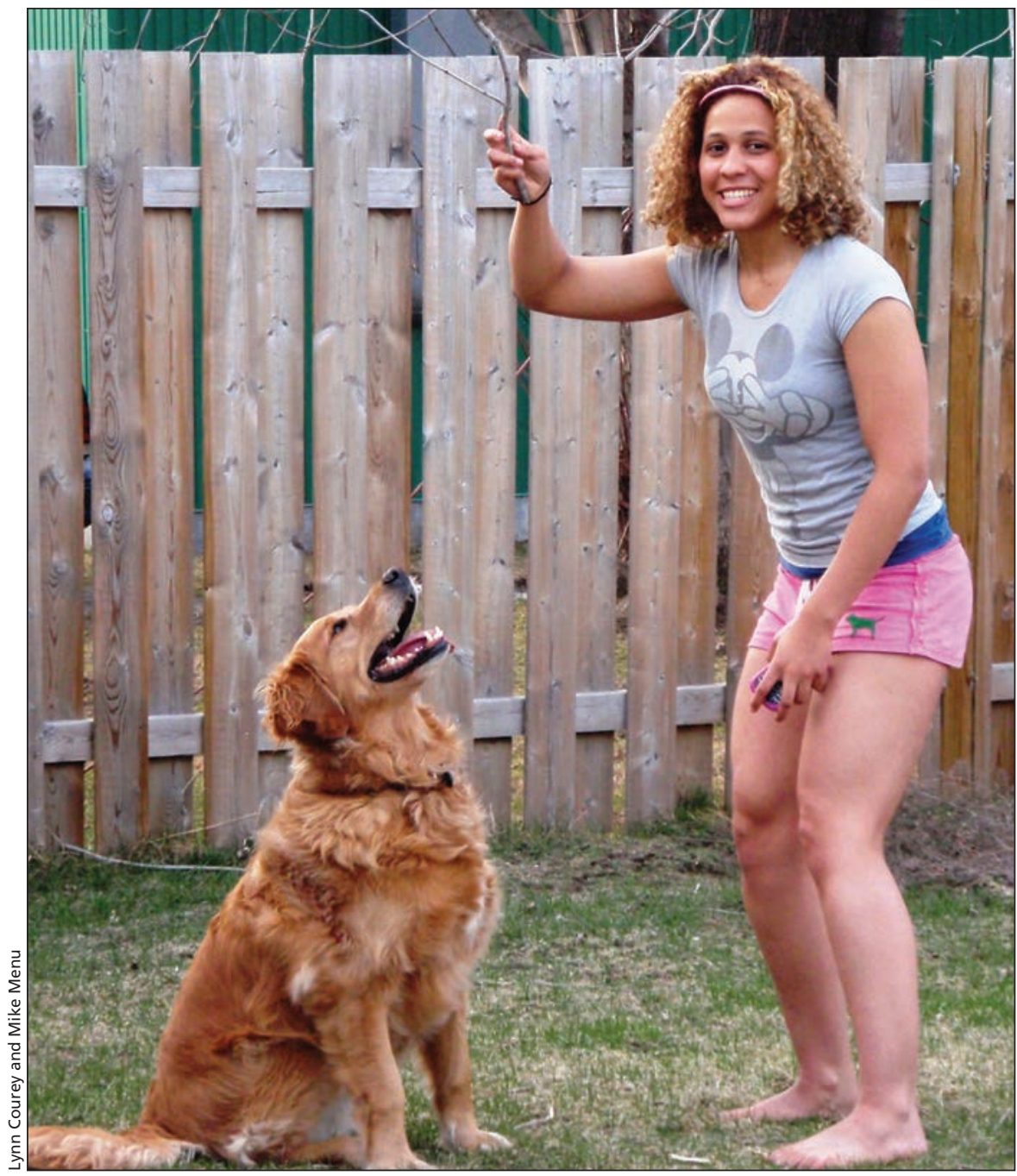

Sasha Menu Courey, who had borderline personality disorder, completed suicide in June 2011. Her parents now advocate for support for the disease.

Courey's parents had never heard of BPD the first time their daughter tried to kill herself. And Courey was never diagnosed in Canada.

Dr. John Gunderson, a Harvard University professor and pioneer BPD researcher says that there is resistance to making the diagnosis. "It's not because it's hard to recognize, but because they fear if they make that diagnosis, patients won't like it, they won't be able to treat it, or they won't be able to get reimbursed. All myths."

Gunderson said patients with BDP have a reputation for being difficult to deal with because traditional psychotherapy and medication is not very effective. However, newer treatments — such as dialectical behavioural therapy (DBT) are validated and effective, but not widely known by physicians and the public.

"While there are experts in borderline personality disorder, it has not entered the general training for psychiatrists around the United States, just like Canada." He said that lack of education about viable treatment options leads professionals to either not diagnose, or, in some cases, misdiagnose the disorder. 
Even when patients are diagnosed, resources for treatment are lacking. In Toronto, which has a population of 2.6 million, there are fewer than 200 public or private in-patient beds for patients with BPD.

Courey's parents grew frustrated trying to find their daughter treatment after a second suicide attempt when she was attending school in Kansas City, Missouri. Basically, there were two options: The Centre for Addiction and Mental Health (CAMH) in Toronto, which has 40 beds for BPD patients, or McLean Hospital, a private institution in Boston. Courey was put on a two-year waitlist at CAMH; McLean's hospital took her right away, at a cost of $\$ 44000$ for 28 days. The treatment was DBT, which Gunderson says is one of the most widely known treatments with the most empirical support to date. DBT combines cognitive behavioural therapy with the Eastern practice of mindfulness. For a disorder that is marked by self-punitive actions, DBT teaches patients to watch their emotions, and avoid becoming attached to them or reacting to them. A December 2010 study in Behaviour Research and Therapy, indicates that DBT is effective in reducing suicide attempts and self-injury.

Although DBT and other therapies, such as mentalization and transference focus have been proven to be effective, the common perception that BPD is untreatable remains.

Courey's parents could not afford to continue her treatment at McLean's. "She ran out of time, she felt like damaged goods," her mother said. Courey completed suicide in June 2011.

Her parents say it was failure to access treatment that contributed to their daughter's suicide. They have been raising awareness about borderline personality disorder and effective treatment options ever since at www.sashbear.org. - Dane Wanniarachige, Windsor, Ont.

CMAJ 2015. DOI:10.1503/cmaj.109-5096 